\title{
A Concept for CFD Simulation of One and Two Phase Flow Compact Heat Exchangers towards the Design Optimization
}

\author{
Fengjun Yang, Klaus Mohrlok \\ Modine Europe $\mathrm{GmbH}$ \\ Arthur-B.-Modine-Straße, D-70794 Filderstadt, Germany \\ Fengjun.Yang@modine.com
}

\begin{abstract}
This article describes a general concept and methodology for the modelling of single phase and two phase flow compact heat exchangers, which enables an economic virtual testing including thermal and hydraulic performances, phase changes, and thermal structural stresses for design optimizations. The main idea of the concept is to split the problem solving process into two steps: the CFD surface characterization with full resolution of a small portion of the periodic geometry and modelling the detailed microscopic physical heat transfer processes; and the global macroscopic CFD conjugate heat transfer calculation by use of the porous media concept. A key issue thereby addressed, besides the flow modelling, is the extraction and representation of the pressure drop and the heat transfer characteristics from the first step and the usage in the second step, especially for two phase flows. As applications of the concept, simulation of different type of heat exchangers, such es chiller, cross flow charge air cooler and radiator are presented and compared with experiments. It can be concluded, that the described concept and approach is feasible to be used for engineering support and multiobjective design optimization of compact heat exchangers.
\end{abstract}

Keywords: CFD conjugate heat transfer calculation, experimental validation, fully developed flow and heat transfer, general concept, multi-objective optimization, single phase flow compact heat exchanger, two phase flow compact heat exchanger

\section{Introduction}

In the trend of vehicle electrification, the design optimization of compact heat exchangers such as radiators, chillers and condensers, which are important components for the vehicle thermal management, play even a larger role than ever.

The traditional 1D simulation code such as EES etc. is very economic, and can serve as the design tool, but it does not provide all the information needed for design optimization. While the 3D CFD and conjugate heat transfer calculations with sophisticated modelling of the detailed real physical processes and phenomena requires huge calculation effort and cost, because of the large amount of complex heat transfer surfaces and the very fine geometric features in heat exchangers. Such an approach, generally speaking, makes a virtual testing or a real multi-objective design optimization in the industry impossible. A solution, which fulfils the economic criteria, and meets all engineering requirements by delivering sufficient detailed information for design optimization, is still a concern for the compact heat exchanger development.

To address the issue, this paper describes at first a concept for the CFD modelling of all compact heat exchangers, regardless whether it is a single phase flow or a two phase flow heat exchanger, whether it deals with incompressible flows or compressible media. And then serval simulation examples of different type of heat exchangers, such as radiator, cross flow charge air cooler, and a chiller are presented as the application of the concept. Thereby the focuses are on the extraction, representation and the usage of flow and heat transfer characteristics of the heat transfer surfaces, especially for the two phase flow heat exchangers in the 3D CFD context.

\section{The Concept for CFD Simulation for All Types Compact Heat Exchangers}

The concept is a unified approach for all types of heat exchangers. It is mainly an extension of the author's work [1] from the one phase flow to the two phase flow heat exchangers. In this approach the design optimization process is generally split to three tasks as shown in Fig. 1.

The first is the microscopic CFD simulation, which can deliver the local characteristics of the heat transfer surfaces in dependence on the local flow and thermal dynamic states. Thereby it is necessary to fully resolve the geometrical features of the heat transfer surfaces as well as the mechanism of the pressure drop and heat transfer in one or two phase flows. As a special further extension and alternative, in some cases, the core characterization is more advantageous than the surface 
characterization, which can deliver the local number of the transfer unit based on a smallest periodic portion of the core including both fluid streams; The second is the macroscopic CFD simulation for conjugate heat transfer. It uses the porous media concept, which enables using the results from task1 as the source terms in the conservation equations for flow and heat transfer to calculate the heat exchanger characteristics and the global physical quantity distributions; Based on results of task 2, the design optimization can be carried out, intuitively or by using a multi-objective optimizer. How the tasks look like in detail is shown with the selected examples as follows.

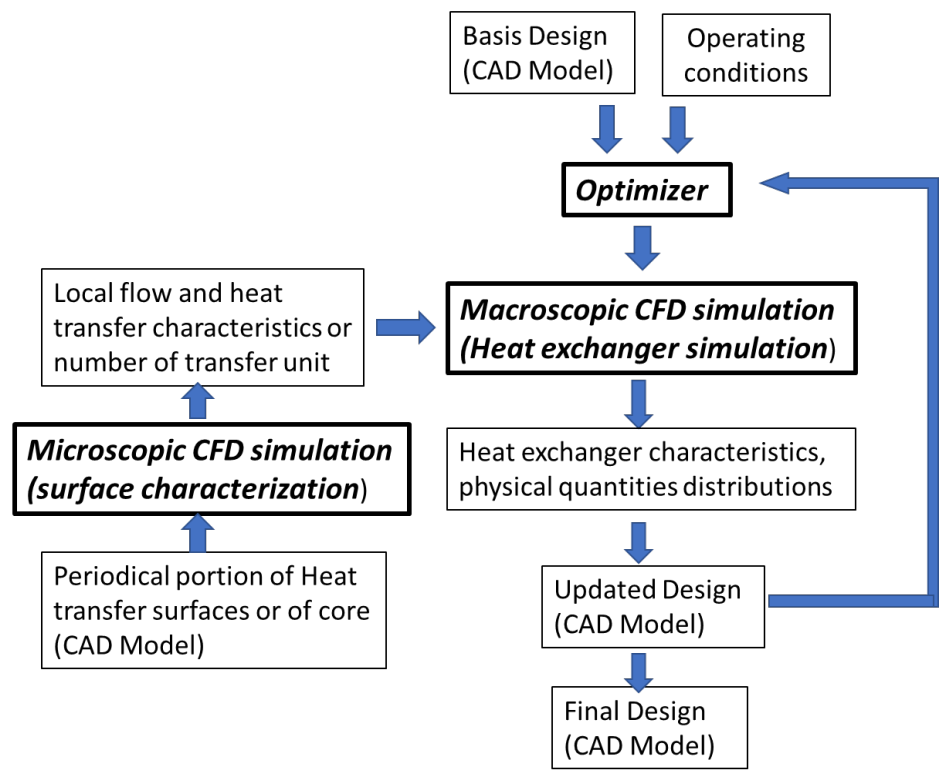

Fig. 1: Overview of the concept.

\section{Performances Calculation of A Cross Flow Charge Air Cooler}

The charge air cooler dealt with here consists of round coolant tubes and dimpled air fins which build up a periodic structure as shown in Fig. 2 (middle \& right). Because of the high density and small feature size of the dimples on the fins in the flow direction the entrance effects are ignorable as the developing flow and heat transfer simulations have shown. The approach in [1] is not easily applicable due to the difficulty of fin efficiency calculation, but it can still be treated as a special fully developed flow and heat transfer case, if instead of a portion of the heat transfer surface a periodical segment of the cooler core is in consideration as mentioned above.

\subsection{Extension of the Fully Developed Flow and Heat Transfer Model}

Surface characterization for constant wall temperature and wall heat flux using the concept of fully developed flow and heat transfer is well known in the literature [2,9]. Fully developed means here, that the velocity distributions are periodical, but the pressure distribution at outlet differs from that at the inlet only by a definite offset, and the convection heat transfer coefficient on the wall at the two locations are the same. By introducing transformations for the pressure and for the temperature, the transformed pressure $\mathrm{p}^{\wedge}$ and temperature $\theta$ will become also periodic (Fig. 2 left):

$$
\begin{aligned}
& \mathrm{p}^{\wedge}(\mathrm{x}, \mathrm{y})=\gamma \mathrm{x}+\mathrm{p}(\mathrm{x}, \mathrm{y}) \\
& \text { with } \gamma=(\mathrm{p}(0, \mathrm{y})-\mathrm{p}(\mathrm{s}, \mathrm{y})) / \mathrm{s} \text { and } \mathrm{s} \text { the periodic distance; } \\
& \theta(\mathrm{x}, \mathrm{y})=(\operatorname{Tw}(\mathrm{x})-\mathrm{T}(\mathrm{x}, \mathrm{y})) /(\operatorname{Tw}(\mathrm{x})-\operatorname{Tb}(\mathrm{x})) \\
& \text { with } \operatorname{Tb}(\mathrm{x}) \text { the bulk temperature and } \operatorname{Tw}(\mathrm{x}) \text { the wall temperature }
\end{aligned}
$$




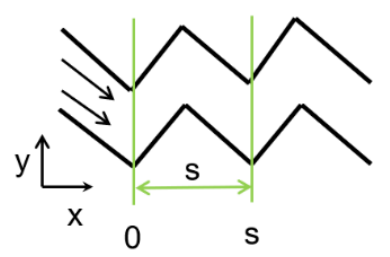

Two dimentional fully devoloped channel flow
Periodic portion of the core of a cross flow charge air cooler

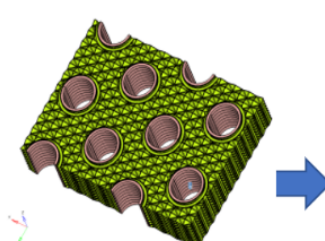

, f

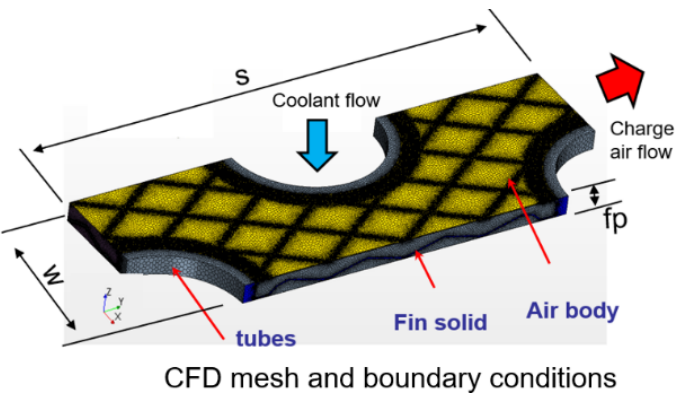

CFD mesh and boundary conditions
For air:

$y=0$ and $y=s$ partial cyclic

$\mathrm{x}=0$ and $\mathrm{x}=\mathrm{w}$ symmetry

$z=0$ and $z=f p$

cyclic

For coolant:

partial cyclic

(Tbulk and htc)

Fig. 2: Flow domains for surface and core characterization

For characterization of the core (Fig. 2, middle \& right) to avoid the difficulties of the fin efficiency calculation as mentioned above, extension has been made: 1) instead of using only one fluid model as in surface characterization, conjugate heat transfer model with both fluid streams and solid tubes and fins (heat transfer unit) is used, and the fins side is resolved by CFD and the tube side heat transfer is calculated with the convection heat transfer coefficient; 2) fully developed means here not only that the heat transfer coefficient of the fin but also that the heat transmission coefficient in the core are periodical; 3) the constant reference temperature (bulk temperature of the second fluid side) is taken as the normalization quantity to transform the partial cyclic to fully cyclic boundary condition instead of the constant heat flux or constant temperature on the heat transfer surface, so that the transformed temperature $\theta^{\wedge}$ is as follows:

$\theta^{\wedge}(\mathrm{x}, \mathrm{y})=(\mathrm{Tr}-\mathrm{T}(\mathrm{x}, \mathrm{y})) /(\mathrm{TR}-\mathrm{Tb}(\mathrm{x}))$

with $\operatorname{Tb}(\mathrm{x})$ as the bulk temperature of the fin side and $\operatorname{Tr}$ as the bulk temperature of tubes flow, $\theta^{\wedge}$ at the wall has a constant value $\mathrm{c}$, but differs from 0 .

Fig. 3 shows the comparison of the temperature distributions between these three types of boundary conditions:

1.Constant heat flux

$$
\begin{aligned}
& \frac{\partial T}{\partial x}=\frac{\partial T_{w}}{\partial x}=\frac{\partial T_{b}}{\partial x} \\
& \mathrm{~T}(\mathrm{x}, \mathrm{y})-\mathrm{Tb}(\mathrm{x})=\mathrm{T}(\mathrm{x}+\mathrm{s}, \mathrm{y})-\mathrm{Tb}(\mathrm{x}+\mathrm{s})
\end{aligned}
$$
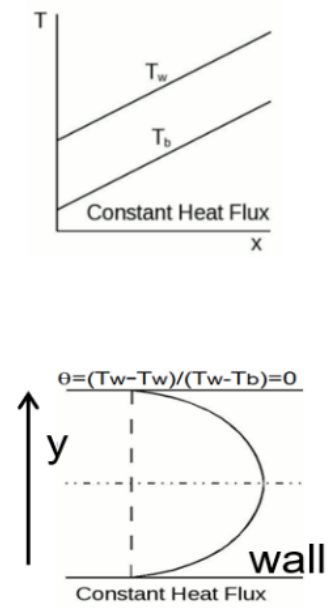

2.Constant wall temperature

$$
\begin{aligned}
& \frac{\partial T}{\partial x}=\theta \frac{\partial T_{b}}{\partial x} \\
& \theta=(T w-T) /(T w-T b)
\end{aligned}
$$
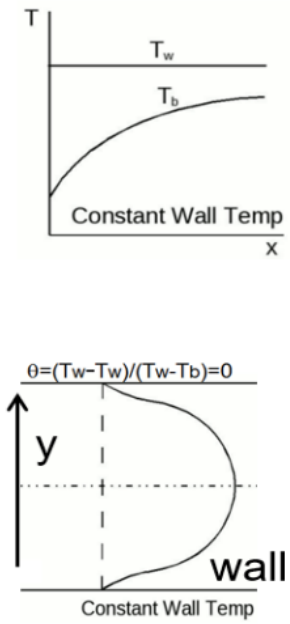

3.Extension: constant reference temperature

$$
\begin{aligned}
& \frac{\partial T}{\partial x}=\hat{\theta} \frac{\partial T_{b}}{\partial x} \quad \theta^{\wedge}=\left(T_{R}-T\right) /\left(T_{R}-T_{b}\right) \\
& \text { dTw } / d x=c d T b / d x
\end{aligned}
$$
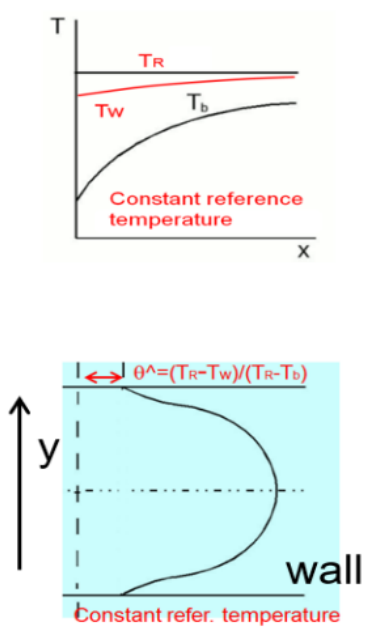

Fig. 3: Temperature distributions in straight ducts for fully developed flows and heat transfers (left and middle from [9]). 


\subsection{Macroscopic simulation of a charge air cooler}

The global macroscopic simulation of the charge air cooler is implemented by using the heat exchanger model in StarCCM+ [3] as shown in Fig.4, which uses the dual cell approach. That means, at the same location there are two one in in the hot flow stream, the other is in the cold flow stream. Both fluid streams are modelled as porous media, their parameters are determined by the obtained pressure drop from the model above. And the heat transfer between the cell can be calculated using the local "number of the transfer unit" known as UA or the local heat conductance of the charge air cooler, which is transformed from heat transmission coefficient out of the same microscopic model.

Fig. 5 shows the calculated flow distributions and Table 1 the calculated characteristics of the whole charge air cooler. The comparison indicates a good agreement between the simulation and measurement. The resource requirement for the calculation is quite low, so that the approach is feasible to be used not only to the conjugate heat transfer performance predictions, but also to the cooler tanks optimizations.

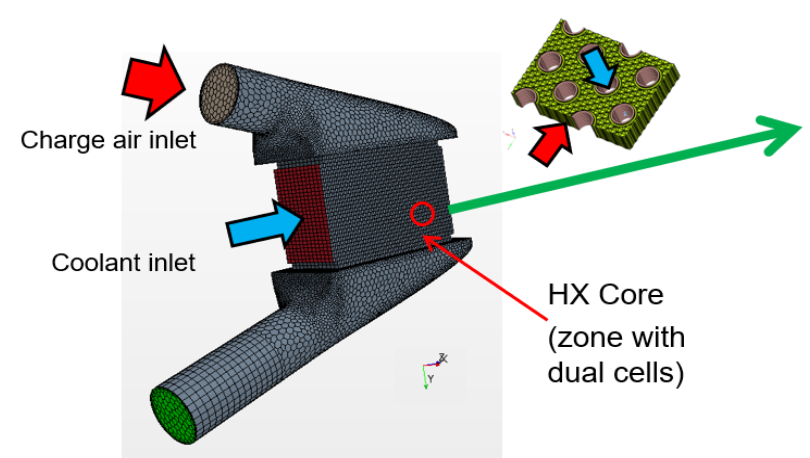

Heat transfer calculation with starCCM+ (dual cell approach), tubes /fin solid not resolved

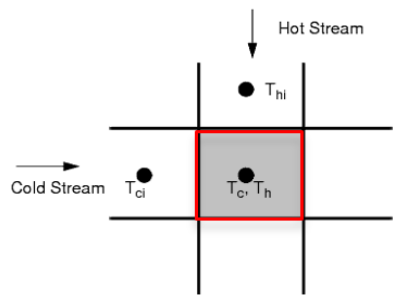

$\dot{m}_{c} C p_{c}\left(T_{c}-T_{c i}\right)=U A_{l}\left(T_{h}-T_{c}\right)$

$\dot{m}_{h} C p_{h}\left(T_{h i}-T_{h}\right)=U A_{l}\left(T_{h}-T_{c}\right)$

$\mathrm{T}_{\mathrm{h}}, \mathrm{T}_{\mathrm{c}}$ are local cell temperatures,

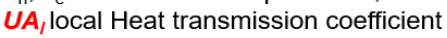

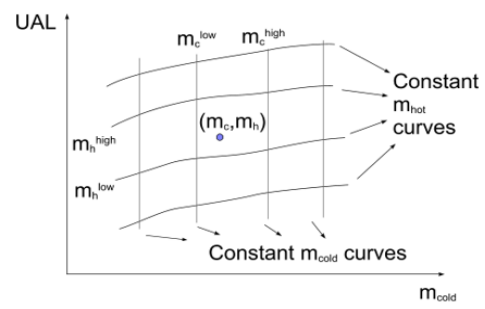

Fig. 4: The macroscopic CFD model of the charge air cooler (right from [3]).

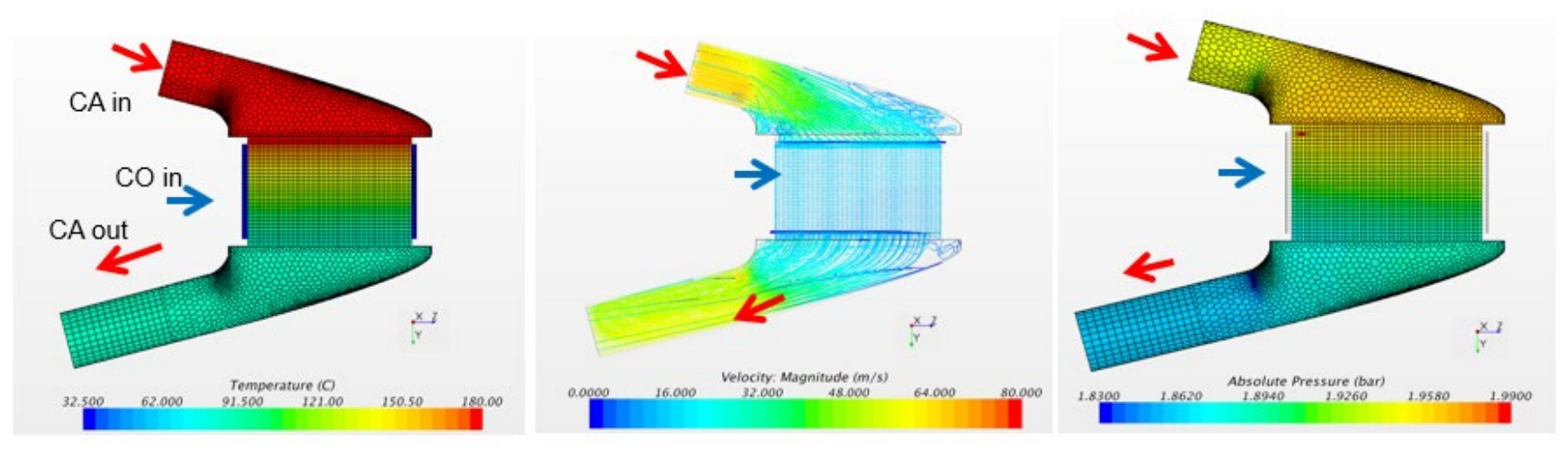

Fig. 5: The calculated streamlines, temperature \& pressure distributions of the charge air. 
Table 1: The calculated characteristics of the charge air cooler in comparison to measurements.

\begin{tabular}{|c|c|c|c|c|c|c|c|c|c|c|c|}
\hline \begin{tabular}{|c|} 
Operating \\
point \\
\end{tabular} & \begin{tabular}{|c|}
$\begin{array}{c}\text { Mflow_air } \\
(\mathrm{kg} / \mathrm{s})\end{array}$ \\
\end{tabular} & $\begin{array}{c}T_{\text {T_air_in }} \\
\left({ }^{\circ} \mathrm{C}\right)\end{array}$ & $\begin{array}{c}\text { T_air_out } \\
\left({ }^{\circ} \mathrm{C}\right)\end{array}$ & $\begin{array}{c}\text { Q_meas. } \\
(\mathrm{kW})\end{array}$ & $\begin{array}{r}Q_{-C F D} \\
(\mathrm{~kW}) \\
\end{array}$ & $\begin{array}{c}\Delta \mathrm{Q} / \text { Q_meas. } \\
(\%)\end{array}$ & $\begin{array}{c}d p \_C F D \\
(\mathrm{hPa})\end{array}$ & $\begin{array}{c}\text { dp_meas. } \\
(\mathrm{hPa})\end{array}$ & $\begin{array}{c}\Delta \mathrm{dp} / \mathrm{dp} \_ \text {meas } \\
(\%)\end{array}$ & $\begin{array}{c}\text { Eff._meas. } \\
(\%)\end{array}$ & \begin{tabular}{|c|} 
Eff._CFD \\
$(\%)$
\end{tabular} \\
\hline$I$ & 0.53 & 180.00 & 5.25 & 48.86 & 50.12 & 2.58 & 87.10 & 85.20 & 2.23 & 60.89 & 62.57 \\
\hline 2 & 0.53 & 179.98 & 117.55 & 35.34 & 33.46 & -5.33 & 93.77 & 92.20 & 1.70 & 44.09 & 41.74 \\
\hline 3 & 0.30 & 180.05 & 76.04 & 30.89 & 31.31 & 1.36 & 30.12 & 30.30 & -0.60 & 68.57 & 69.49 \\
\hline
\end{tabular}

\section{Conjugate Heat Transfer Calculation of a Compact Two Phase Flow Heat Exchanger}

The heat transfer surfaces of the refrigerant side in a compact two phase flow heat exchanger such as chillers and condensers consist usually of dimples and fins. Although the geometry shows also a periodic structure both in the flow direction and in the cross direction, for the surface characterization, however, it cannot be treated as fully developed flow and heat transfer as in [2,9], because of the strong coupling between them, and because the vapor quality and flow forms as well as heat transfer changes strongly in the flow direction.

But for the CFD microscopic modelling, the CFD calculation domain can still be dramatically reduced in comparison to calculating a whole heat exchanger by using only one periodic strip of a two phase flow channel in the cross flow direction. In addition, there are also only a few heat transfer surfaces to be used for heat exchanger designs.

Although the concept is in principle the same as the general method for single phase flow heat exchangers proposed by F. Yang [1] et al., the modelling for the microscopic and macroscopic calculation is but much complicated here. The microscopic modelling of the two phase flow and heat transfer mechanisms is still under further development and its existing model parameters have also a limited validated application ranges and cases, so that it is very beneficial to get the surface characterization from the experimental investigations, if it is possible.

\subsection{CFD Microscopic Modelling Of Two Phase Flow and Heat Transfer}

The microscopic simulation for the surface characterization is carried out by using StarCCM+ [4]. The flow is described by the Eulerian two phase flow model with S-Gamma modelling of transport phenomena. Two sets of different physical state variable are thereby used in features of multiphase segregated flow and multi flow regime. It enables bubble / droplet breakup and coalescences to resolve the bubble / droplet size and its density distributions. To catch the heat transfer mechanism, the bubble formation, condensation, quenching and local convection are modelled for both the wall and bulk boiling in subcooled or saturated refrigerant as well as droplet evaporation in wet and superheated vapor as shown in Fig. 6.
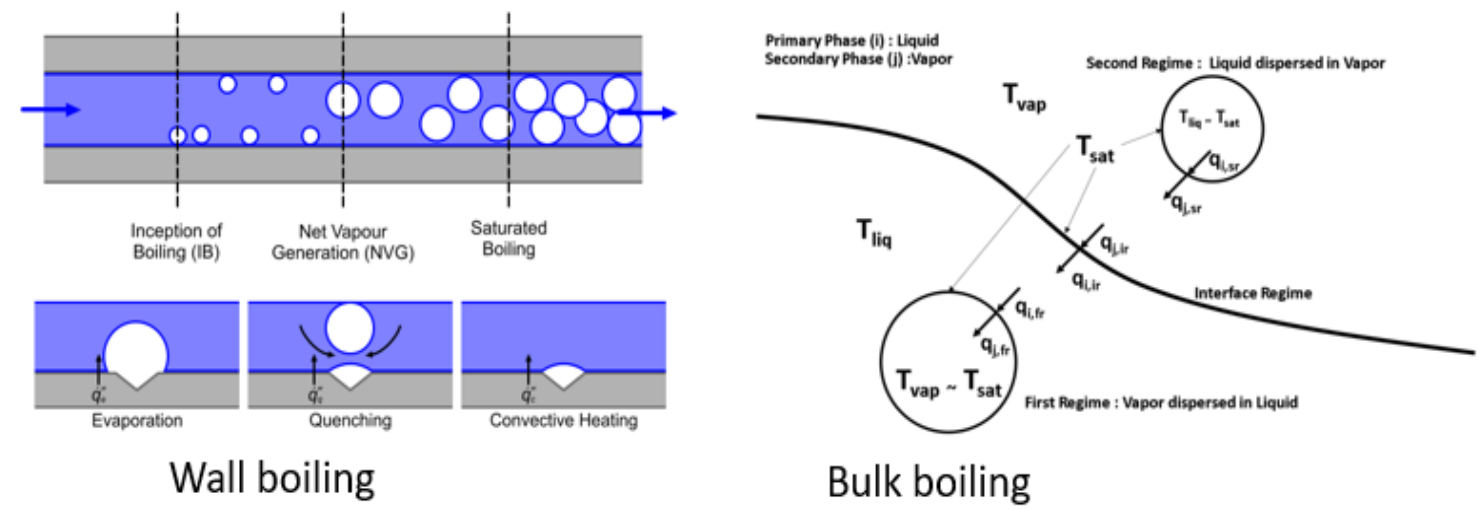

Fig. 6: The microscopic two phase flow modelling [4]

Fig. 7 shows an example of the surface characterization by using the microscopic CFD described above. It can be clearly seen, the vapor quality change, the droplet size and density distributions changes in the flow direction. Simulations show, for small channel height and large velocity (large Froud number), the gravity plays almost no role, and a saturated boiling /bulk boiling takes place as an annular type of two phase flow for low wall heat flux. 


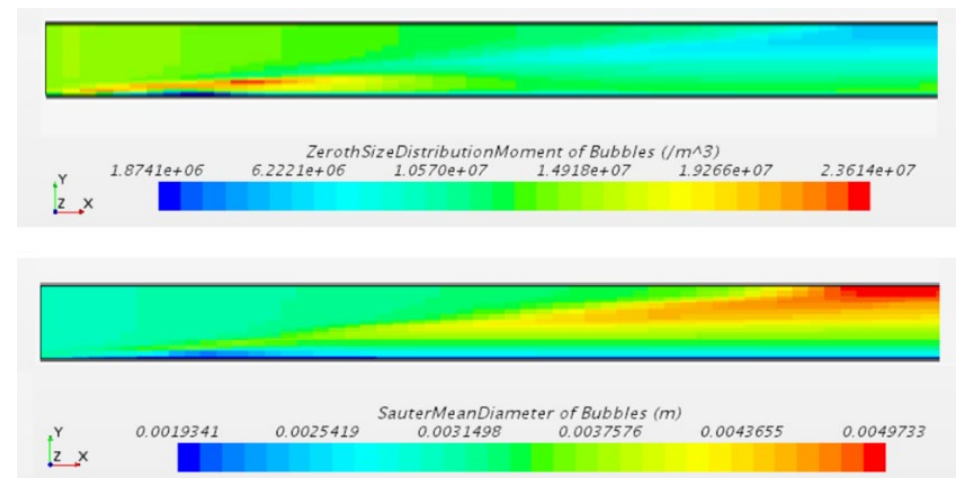

Fig. 7: Bubble number and diameter distributions for the two phase flow heat transfers in a heated channel flow

\subsection{Extraction and Representation of the Surface Characterization for Two Phase Flows from CFD Calculations and Measurements}

The two phase flow and heat transfer characteristics obtained from the microscopic simulation or measurements are complicated and need a proper representation. In the literature, numerous models are available, a famous one among them is the Shah correlation [5], but it is developed for round smooth tubes.

Because the flow regime and heat transfer mechanisms classifications are almost the same for round tubes and other complex heat transfer surfaces, which are dependent on the "local" Froud, convection and boiling numbers, so that the Shah model structures could be expected still valid for other types of surfaces, but the model parameters will be largely departed from the original data set. The single phase flow pressure drop and heat transfer for the same heat transfer surface, on which the two phase flow correlations based, should be derived from the real surfaces instead of those for round tubes. Then the modelling task turns to a problem of the parameter estimations as in the control theory.

Fig. 8 shows the macroscopic modelling and the parameter estimation processes. At first, a set of microscopic CFD calculations or real sample testing is to be carried out with a set of representative inlet conditions (such as pressure, temperature, vapor quality and mass flow rate) to get a set of outlet state variables (such as pressure, vapor quality, temperature or superheat). Then an optimization loop is to be started, which consists mainly of the macroscopic simulations of the same sampling for the same geometry and inlet conditions, and of the parameter estimation by the optimizer. If the model parameters are converged, the macroscopic model will be ready to be used in a real simulation of a two phase flow heat exchanger designed with the characterized heat transfer surface.

\subsection{Macroscopic Simulation of Two Phase Flow Heat Exchangers by Using the Porous Media Concept}

For the macroscopic simulation, the refrigerant is modelled as Eulerian two phase flow, and the coolant as conventional one phase turbulent flow by using the porous media concept, in which the heat transfer and the pressure drop are treated as sources in the conservation equations of the two phase flows in VOF formulation and the phase changes fulfil the thermodynamic equilibrium conditions.

For the pressure drop, the model structure of the Grönnerud correlation [6] and for the heat transfer the Shah correlation [5] are taken, whose parameters are estimated as described in the last chapter by using the sample testing (or CFD) data.

Several validation projects have been carried out. Fig. 9 shows representatively the calculated solid temperature and refrigerant vapor quality distributions and Table 2 the calculated operating point in comparison with the measurements. They agree well with each other. Also to mention is, that engineering supports using this procedure have led to significant chiller design improvement. 


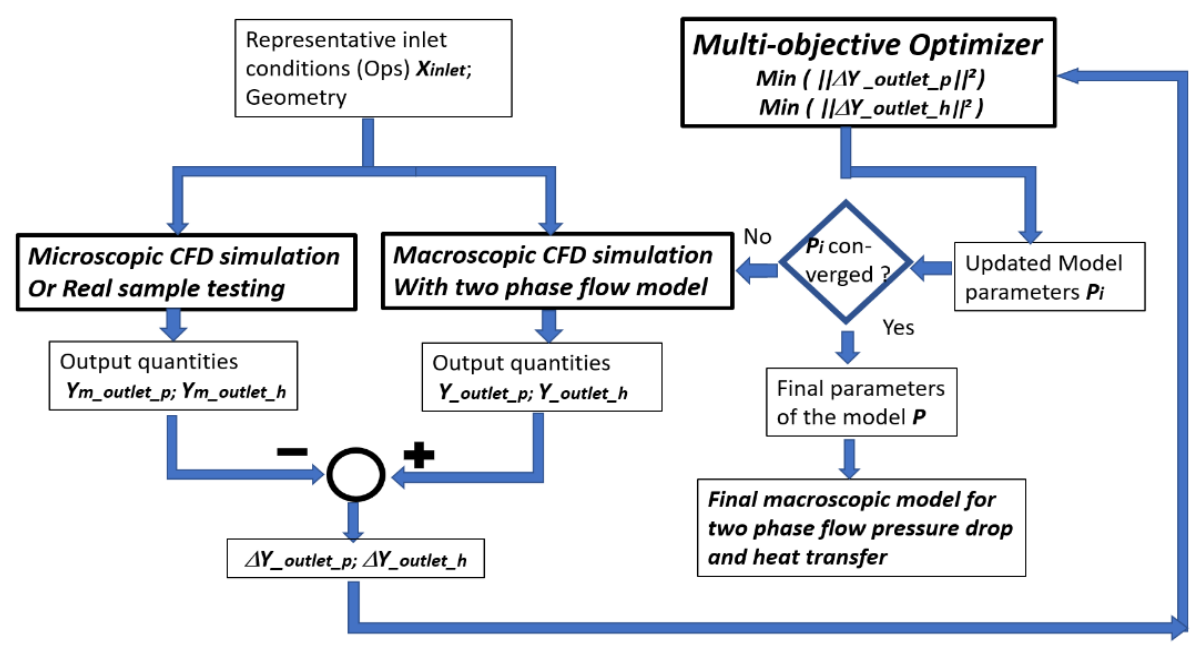

Fig. 8: Macroscopic model and the parameter estimation
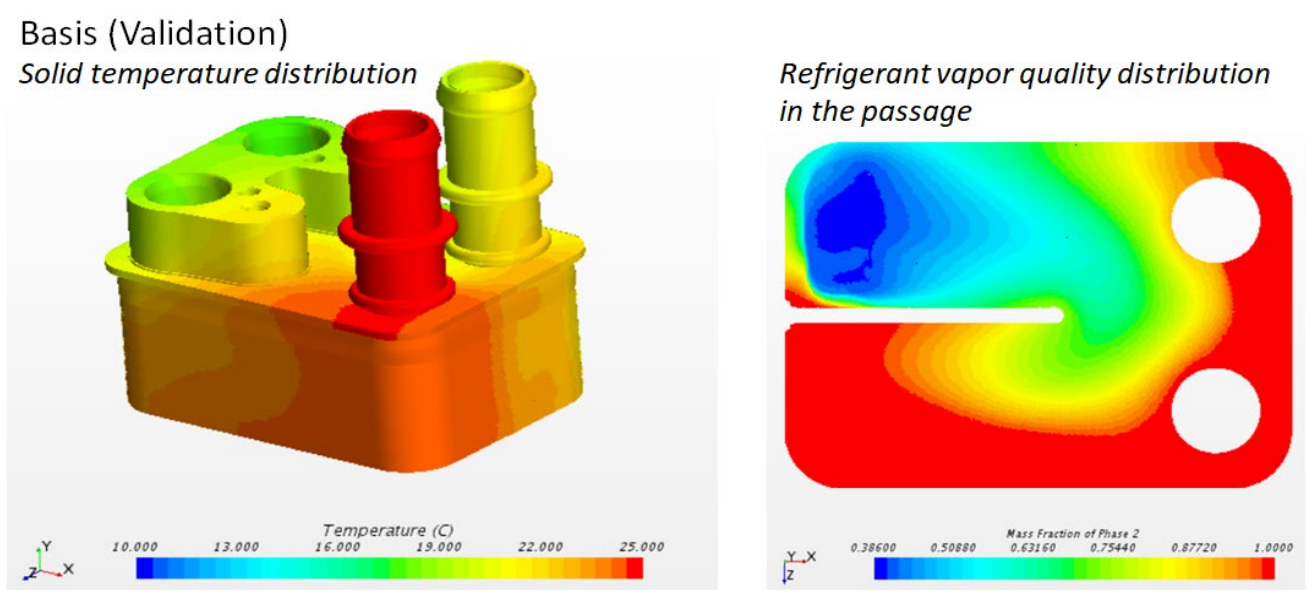

Fig. 9: The calculated solid temperature and refrigerant vapor quality distributions

Table 2: The CFD calculation and validation of the chiller characteristics

\begin{tabular}{|c|c|c|c|c|c|c|c|c|c|c|c|c|c|c|c|c|}
\hline & & & & Coolant & & & & Refrigerant & & & & & & CFD results & & \\
\hline \multirow[t]{2}{*}{ Chiller } & OP & T_inlet & p_inlet & V. flow rate & M. flow rate & T_inlet & p_inlet & V. flow rate & M. flow rate & X-inlet & dp_coolant & dp_Refri. & p_out_Refri. & X - out Refr. & SH_out Refr. & heat transfer \\
\hline & & 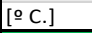 & [bar-a] & [L/hr] & {$[\mathrm{kg} / \mathrm{s}]$} & [으.] & [bar-a] & {$[\mathrm{kg} / \mathrm{hr}]$} & {$[\mathrm{kg} / \mathrm{s}]$} & & {$[\mathrm{hPa}]$} & {$[\mathrm{hPa}]$} & {$[\mathrm{hPa}]$} & & [o C.] & {$[\mathrm{kW}]$} \\
\hline \multirow[t]{2}{*}{$\begin{array}{c}\text { Basis } \\
\text { (Validation) }\end{array}$} & 1 & 24.9 & 2.5 & 999.9 & 0.3 & 5.0 & 3.7 & 182.6 & 0.1 & 0.4 & 161 & 378 & 3352 & 1 & 6.0 & 4.9 \\
\hline & & & & Coolant & & & & Refrigerant & & & & & & Measuremen & & \\
\hline \multirow[t]{2}{*}{ Chiller } & OP & T_inlet & p_inlet & V. flow rate & M. flow rate & T_inlet & p_inlet & V. flow rate & M. flow rate & X-inlet & dp_coolant & dp_Refri. & p_out_Refri. & X-out Refr. & SH_out Refr. & heat transfer \\
\hline & & {$\left[\begin{array}{ll}0 & C\end{array}\right]$} & [bar-a] & {$[\mathrm{L} / \mathrm{hr}]$} & {$[\mathrm{kg} / \mathrm{s}]$} & {$\left[\begin{array}{ll}0 & C\end{array}\right]$} & [bar-a] & {$[\mathrm{kg} / \mathrm{hr}]$} & {$[\mathrm{kg} / \mathrm{s}]$} & - & {$[\mathrm{hPa}]$} & {$[\mathrm{hPa}]$} & {$[\mathrm{hPa}]$} & - & {$[0 \bar{C}]$.} & {$[\mathrm{kW}]$} \\
\hline $\begin{array}{c}\text { Basis } \\
\text { (Validation) }\end{array}$ & 1 & 24.9 & 2.5 & 999.9 & 0.3 & 5.0 & 3.7 & 182.6 & 0.1 & 0.4 & 157 & 420 & 3350 & 1 & 5.5 & 0 \\
\hline
\end{tabular}




\section{Shape Optimization of A Radiator Tank by Using A Multi-Objective Optimizer}

By using the concept described in this paper, the generated macroscopic CFD models of the compact heat are generally small as shown above, and the calculation for one geometry variation per operating point lasts only a few on a normal workstation, so it is feasible and economical to run a multi-objective optimization to get the optimized shape the components of the heat exchanger based on the already optimized core [7].

To illustrate the process, the optimization of radiator inlet tank is taken as an example. The problem can be mathematically formulated as by changing the inlet tank geometry to minimize the three objectives: 1 . the pressure drop of the radiator; 2. the inhomogeneity of the flow distributions over the tubes (standard deviation of the mass flow rates of the tubes) and 3. the tank volume.
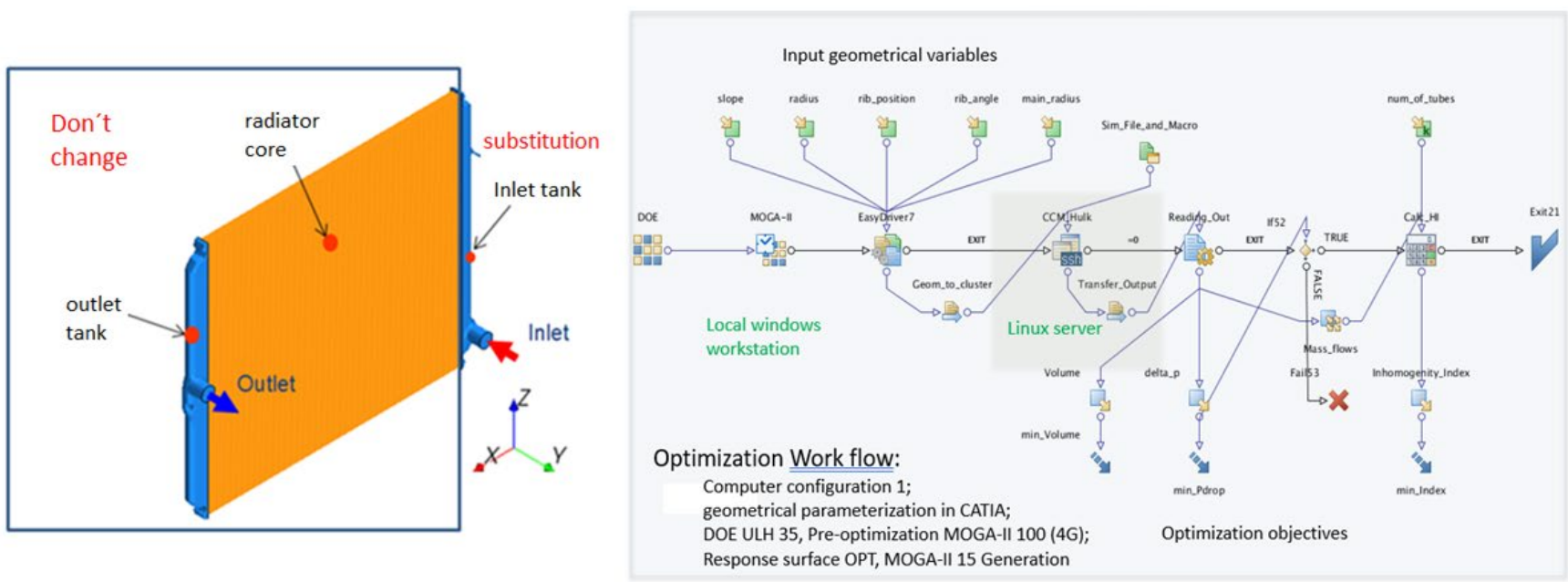

Fig. 10: The Macroscopic CFD model and Flow chart for optimization in modeFrontier.

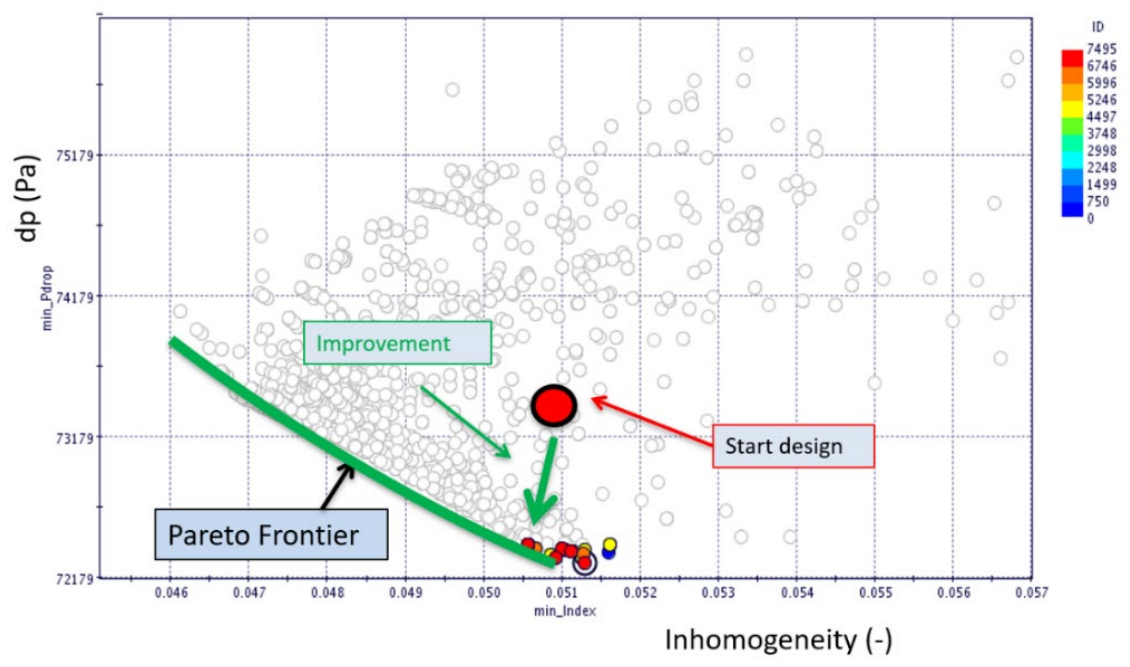

Fig. 11: The Pareto Frontier and the Optimum in the objective space.

To keep the meshing and modelling effort in limit, the core and the outlet tank are pre meshed and setup as a macroscopic CFD model, only the inlet tank, which is parametrized in CAD (CATIA), needs to be varied by the optimizer during the optimization process as shown in Fig 10, left. Fig. 10 right shows the process implemented in 
modeFrontier [8]. The optimizer and the CAD tool for geometries generation run here on a local workstation and the CFD simulations are carried out on a remote Linux cluster. For robust and economic calculations the MOGA-II optimization algorithm and response surface techniques are used.

Fig. 11 shows the Pareto frontier in the objective space, generated by the optimization algorithm. Each point on the frontier can be taken as an optimum, dependent on a subjective weighting of each of the concurrent objectives. Under the given constraints, the smaller inhomogeneity of the mass flow distribution, means a better heat transfer, is connected with some more pressure drop; if the minimal pressure drop is the prime concern, then the coloured point is the target.

In comparison to the manually optimized design, the optimization of the geometry using modeFrontier has achieved a further pressure drop decrease in the inlet tank by approximately $8 \%$ for the give case.

\section{Conclusion}

The presented concept allows an effective virtual testing and optimization of all types of compact heat exchangers with single phase or two phase flow heat transfer.

Based on the introduced extension of the fully developed flow and heat transfer for a cross flow charge air cooler core, the cost and runtime for the CFD performance characteristics calculation could be drastically reduced by using the macroscopic CFD modelling.

The presented methodology for two phase flow heat exchanger modelling, which consists of the microscopic heat transfer surfaces characterization and the macroscopic modelling of the two phase flow heat transfer in a compact heat exchanger as well as of the representation and the parameter estimation by the introduced scheme, makes the simulation of a two phase flow heat exchanger possible in the engineering point of view. Because of the low calculation resources requirements, it is could be used in the context of the multi-objective optimization.

For transient heat transfer problems in connection with structural thermal fatigue analysis, the concept described here can also be used in combination with other acceleration methods such as co-simulation techniques, which separates the physics model to different calculation domains according to its time constant for flow and heat transfer, in order to reduce the calculation time and cost further.

\section{References}

[1] F. Yang, K. Mohrlok, U. Schäffer, R. Stier, "A concept for the integrated 3D flow, heat transfer and structural calculation of compact heat exchangers," in Proceedings of the 13th International Conference on Simulation and Experiments in Heat Transfer and its Applications, A Coruña / Spain, July 2014.

[2] S.V. Patankar. C.H. Liu, E.M. Sparrow, "Fully developed flow and heat transfer in ducts having streamwise-periodic variations of cross-sectional area," in Journal of Heat Transfer, vol. 99(2), pp180-186, 1977.

[3] "Modelling Heat Exchangers," in StarCCM+ User Manual V12.06, Siemens Product Lifecycle Management Software Inc., 2017.

[4] "Theory of Eulerian Multiphase Flows," in StarCCM+ User Manual V12.06, Siemens Product Lifecycle Management Software Inc., 2017.

[5] M. M. Shah, "Chart correlation for saturated boiling heat transfer: equations and further study," in ASHRAE Trans., vol. 88(1), pp185-196, 1982.

[6] R. U Grönnerud, "Investigation of liquid hold-up, flow-resistance and heat transfer in circulation type evaporators, part IV: two-phase flow resistance in boiling refrigerants," in Annexe 1972-I, Bull. de I'Inst. du froid, 1979.

[7] F. Yang, F. Opferkuch, "CFD Optimization of Heat Exchangers with Regard to their Fine Structures," in Proceedings of the 1st modeFrontier Users' Meeting in Germany, Stuttgart, Oct, 2007.

[8] ModeFrontier User Manual, V 4.6.0, EnginSoft Company, 2014.

[9] "Modelling Fully Developed Flow and Energy," in StarCCM+ User Manual V12.06, Siemens Product Lifecycle Management Software Inc., 2017. 